\title{
Os livros didáticos de História do Brasil para o Ensino Secundário na Era Vargas: entre autores, didáticas e programas curriculares
}

\author{
Textbooks of History of Brazil for High School in Vargas Era: \\ between authors, teachings and curricula \\ Los libros didácticos de Historia del Brasil para la Enseñanza Secundaria en la \\ Era Vargas: entre autores, didácticas y programas curriculares
}

\author{
KÊNIA HILDA MOREIRA ${ }^{1}$
}

\section{Resumo}

Objetiva-se analisar o livro didático de História do Brasil destinado ao ensino secundário na Era Vargas com ênfase para as relações entre autores, didáticas e programas curriculares, na perspectiva da história da educação. Para tanto, apresenta-se uma análise de conteúdos e das concepções pedagógicas em relação a dois autores e seus respectivos títulos didáticos. Constatou-se na pesquisa algumas particularidades sobre os livros didáticos nesse período: O "método renovado" se sobressai enquanto conteúdo didáticopedagógico; algumas abordagens no livro didático antecedem os programas curriculares; e a presença de trechos de discursos do presidente Getúlio Vargas reforçam a valorização da "Revolução de Outubro de 1930" nos referidos livros. O que nos permite concluir, em conformidade com Choppin (1992), que o livro didático como instrumento pedagógico inscrito em uma longa tradição, é inseparável das condições de ensino de seu tempo.

Palavras-chave: História do Brasil. Era Vargas. Ensino Secundário. Livro didático.

\footnotetext{
${ }^{1}$ Doutora em Educação pela Universidade Estadual Paulista, Campus de Araraquara, em São Paulo, Brasil. Professora de História da Educação na Universidade Federal da Grande Dourados, em Mato Grosso do Sul, Brasil. E-mail: keniamoreira@ufgd.edu.br
} 


\begin{abstract}
This text aims to analyze the textbooks History of Brazil for high school in Vargas Era (1930-1945) with emphasis on the relationship between authors, teachings and curricula in the perspective of Brazilian education history. For both we selected three textbooks of two authors. We found some peculiarities about the textbooks in this period: the "new method" stands as didactic and pedagogical content; some approaches in the textbook precede to the curricula; and the presence of President Getúlio Vargas speeches reinforce the value of the "October Revolution of 1930" in these textbooks. This allows us to conclude, in line with Choppin (1992), the textbook as an educational instrument inscribed on a long tradition, is inseparable from teaching conditions of his time.
\end{abstract}

Keywords: History of Brazil. High School. Vargas Era. Textbooks

\title{
Resumen
}

El objetivo es analizar el libro didáctico de Historia del Brasil destinado a la enseñanza secundaria en la Era Vargas con énfasis en las relaciones entre autores, didácticas y programas curriculares, en la perspectiva de la historia de la educación. Para eso, se presenta un análisis de contenido de las concepciones pedagógicas en relación a dos autores y sus respectivos títulos didácticos. Se constatan en la investigación algunas particularidades sobre los libros didácticos en ese periodo: el "método renovado" se resalta en cuanto contenido didáctico-pedagógico; algunos abordajes en el libro didáctico anteceden los programas curriculares; y la presencia de trechos de discursos del presidente Getulio Vargas refuerzan la valorización de la "Revolución de Octubre de 1930" en los referidos libros. Lo que nos permite concluir, en conformidad con Choppin (1992), que el libro didáctico como instrumento pedagógico inscrito en una larga tradición, es inseparable de las condiciones de enseñanza de su tiempo.

Palabras-clave: Historia del Brasil. Era Vargas. Enseñanza Secundaria. Libro didáctico. 
A Era Vargas, entre 1930 e 1945, é conhecida como um período de expansão do ensino secundário no Brasil, reformulado pelo governo federal, que, por sua vez, passa a estabelecer os programas dos cursos e suas instruções metodológicas. Nesse sentido, nosso objetivo é apresentar um olhar para o livro didático de História do Brasil destinado ao ensino secundário nesse contexto, em busca, não de prescrever, criticar e denunciá-lo, como questiona Soares (1996, p. 54), mas de investigar, descrever e compreendê-lo.

Trata-se de questionar o que 'foi' o livro didático de História do Brasil no período delimitado, com ênfase para as relações entre autores, didáticas e programas curriculares, na perspectiva da história da educação brasileira. Para tanto, apresentamos uma análise de conteúdos e das concepções pedagógicas tomando como objeto títulos didáticos de dois autores situados na Era Vargas: Epitome de História do Brasil, de Jonathas Serrano (1941, $1^{\text {a }}$ edição de 1933), e História do Brasil para o terceiro ano ginasial e História do Brasil para o quarto ano ginasial, de Joaquim Silva $(1943 ; 1944)^{2}$.

Ao analisarmos o ensino de História do Brasil pelos livros didáticos, consideramos a disciplina escolar não como vulgarização ou adaptação das ciências de referência, e sim como produto específico da escola, o qual, segundo Julia (2001), coloca em evidência o caráter criativo do sistema escolar, segundo a abordagem proposta pela História das Disciplinas Escolares apresentada por Chervel (1990).

Para fins teórico-metodológicos, compreendemos o livro didático como aquele constituído de um conjunto extenso de conteúdos curriculares, com progressão em unidades, favorecendo usos coletivos e individuais (CHOPPIN, 1992). E também como instrumento pedagógico inscrito em uma longa tradição, inseparável tanto na sua elaboração como na sua utilização das estruturas, métodos e condições do ensino de seu tempo.

Ao pensarmos no referencial de análise do corpus selecionado, estivemos atentos a não colocar à prova determinados modelos teórico-conceituais, em detrimento do escrutínio da hermenêutica documental (MONARCHA, 2007). Desse modo, compreendemos o livro didático como representação dos campos epistêmico e científico, pedagógico, sociológico e antropológico, constituindo um caso particular no quadro da cultura escrita, da cultura escolar e da escolarização. De outro modo, propomos uma análise considerando a necessidade de abordagem específica, fazendo emergir uma etnohistoriografia (MAGALHÃES, 2006), em que sobressaia um historicismo que determine o sentido e a orientação da investigação.

Para apresentar nossas questões, dividimos o texto em três partes. Na primeira, levantamos algumas questões em torno do surgimento dos programas curriculares de História do Brasil entre os ministérios de Francisco Campos e Gustavo Capanema; na segunda, apresentamos os autores e obras selecionadas; na terceira, procedemos a uma análise do conteúdo histórico e didático dessas obras.

\footnotetext{
${ }^{2}$ Os critérios de seleção foram os mesmos apresentados em Moreira (2011), ou seja, consideramos os livros didáticos de História do Brasil de maior circulação no período.
} 


\section{Reformas do Ensino Secundário e programas para o ensino de História do Brasil na Era Vargas}

A reforma Rocha Vaz, de 1925, estabeleceu a implantação generalizada de um ensino ginasial, seriado, com frequência obrigatória e ampliação das funções normativas e fiscalizadoras da União, preparando a implantação definitiva do ensino secundário como curso regular. Entretanto, questões econômicas e de mentalidade dificultaram a efetivação do ensino secundário regular seriado. Caberiam às reformas posteriores, executadas pelos ministros Francisco Campos (1931-1934) e Gustavo Capanema (1934-1945), durante a Era Vargas, a institucionalização do ensino secundário regular no Brasil.

A Era Vargas introduziu mudanças significativas no ensino secundário, instituindo um sistema educacional de nível nacional, ao contrário dos anos iniciais da República, em que os esforços foram direcionados para o ensino primário. A Tabela 1 demonstra a expansão do ensino secundário entre 1930 e 1945.

Tabela 1: Matrícula Escolar no Brasil de 1930 a 1945

\begin{tabular}{c|c|c}
\hline Ano & Primário & Secundário \\
\hline 1930 & 2.084 .000 & 83.000 \\
\hline 1935 & 2.413 .594 & 93.829 \\
\hline 1940 & 3.302 .830 & 170.057 \\
\hline 1945 & 3.496 .664 & 256.467 \\
\hline
\end{tabular}

Fonte: Hallewel (2005, p. 375)

A reforma empreendida por Francisco Campos conferiu organicidade ao ensino secundário ao estabelecer currículo seriado, frequência obrigatória e diploma para ingresso no superior. Antes predominava o sistema de "preparatórios" e exames parcelados (ROMANELLI, 1978; CUNHA, 1980). A partir de 1931, as normas administrativas e programáticas do ensino secundário foram centralizadas no Ministério da Educação e Saúde Pública.

Cabe lembrar os conflitos entre católicos e escolanovistas que influenciaram a implantação de tal reforma. Francisco Campos encontrou resistências e desconfianças por parte da Igreja Católica e para contorná-las permitiu a oferta do ensino religioso e estabeleceu o reconhecimento oficial para as escolas mantidas pelas municipalidades, associações e particulares. Tais conflitos ajudam a compreender a existência de discursos católicos nos livros didáticos analisados, como veremos adiante.

O ensino secundário ficou organizado em dois ciclos: curso fundamental ou ginasial, com duração de cinco anos, e curso complementar, de dois anos. Quanto aos programas de ensino, a reforma estabeleceu os currículos dos cursos e suas instruções metodológicas. Findava o monopólio do Colégio Pedro II e demais instituições no tocante à formulação de programas. 
A reforma previa ainda uma Faculdade de Educação, Ciências e Letras que chegou a ser criada pela legislação. Todavia a formação do magistério para o secundário, e nela a formação de professores para o ensino de História, seria concretizado pela Universidade de São Paulo (USP), 1934, e pela Universidade do Distrito Federal (UDF), $1935^{3}$.

A demanda de professores para o magistério secundário era maior do que a oferta de ensino superior, e a proporção dos licenciados era inferior a $20 \%$ da demanda. No entanto, em 1936, por exemplo, apenas oito alunos foram graduados em História e Geografia na primeira turma da $\mathrm{USP}^{4}$.

Durante o ministério de Gustavo Capanema, ficou estabelecido que os programas de ensino fossem livres, claros e flexíveis, indicando tão-somente o sumário e as diretrizes da disciplina. Os conteúdos eram dispostos em "unidades temáticas", todavia, note-se, a prática das "unidades" encontrou obstáculos frente à tradição de conteúdos isolados.

Com duração de sete anos, o secundário comportava curso ginasial, quatro anos, e colegial, com três, organizado em clássico e científico.

No que diz respeito especificamente aos programas de História do Brasil, é preciso lembrar que o recorte temporal inicial aqui delimitado corresponde a um período de discussões em torno de um ensino de História nacional ou universal.

A reforma do ensino secundário de 1931 restabeleceu a História da Civilização integrada a História Geral e História do Brasil e da América. Em Como se ensina História, Jonathas Serrano (1935) concluiu pela inexequibilidade do ensino de História da Civilização, uma vez que o número de pontos aumentara e o número de aulas diminuíra; e ainda, que "o título de alguns pontos é pouco feliz" [...] "se os autores de reformas e programas fossem obrigados a lecionar, sentiriam melhor a inexequibilidade de certas exigências teóricas, sem fundamento na experiência" (Ibid., p. 28-29). A medida gerou debates sobre o ensino de História, onde afloravam questões, inclusive, sobre a sociedade a ser reconstruída na Era Vargas.

O tema do universalismo era um dos destaques nos meios educacionais brasileiros e internacionais. O tema estava em correspondência com o movimento internacional pela paz mundial iniciado após a Primeira Guerra, em substituição ao espírito nacionalista avaliado como agressivo e belicoso ${ }^{5}$.

Atribuía-se à educação escolar papel decisivo na formação de mentalidades pacifistas e universalistas. É aí que o ensino de História e seus livros didáticos recebem interferência de comissões internacionais criadas para a consecução de tal finalidade. Surgia um clima propício à rediscussão e reavaliação dos estereótipos nacionalistas depreciadores da imagem de certas nações ${ }^{6}$.

\footnotetext{
${ }^{3}$ Cf. Nagle (1976) e Lacombe (1973).

${ }^{4}$ Dados do Arquivo da Seção de Alunos da Faculdade de Filosofia, Letras e Ciências Humanas da USP, Cf. Bittencourt (1990).

${ }^{5}$ Exemplo desse movimento são os eventos em capitais sul-americanas: Congresso Científico Panamericano, Lima, 1924; Congresso Universitário Sul-Americano, Montevidéu 1931; $7^{\text {a }}$ Conferência Panamericana, Montevidéu, 1933; Conferência Interamericana de Consolidação da Paz, Buenos Aires, 1936; $2^{\circ}$ Congresso Internacional de História da América, Buenos Aires, 1937; e $2^{\text {a }}$ Conferência Americana de Comissões Nacionais de Cooperação Intelectual, Havana, 1941.

${ }^{6}$ Para Leite (1969), a análise dos livros didáticos a cargo da UNESCO mostrou que o defeito da maioria dos livros didáticos residia na tendência a monopolizar as virtudes de um país e atribuir a responsabilidade dos conflitos e retrocessos aos inimigos da nacionalidade. Em 1933 o Brasil firmou convênio com a Argentina para revisar os textos de História e Geografia, como resultado criaram-se comissões revisoras dos didáticos em ambos os países.
} 
O Instituto Histórico e Geográfico do Brasil (IHGB) participou dos debates, recebeu e expediu notificações e serviu de reação à perspectiva universalista. Em 1934, Max Fleiuss, secretário-geral do IHGB, expôs em memorial as razões para a inclusão da História do Brasil no curso secundário; alegava que a exclusão poderia originar um povo órfão de caráter (FLEIUSS, 1934 apud RESNIK, 1992). A. F. Cesarino Jr, membro do IHGB, profere palestra nesta instituição em defesa da reinclusão da cadeira de História Pátria para cimentar a unidade cultural da população brasileira.

Wanderley Pinho, membro do IHGB e deputado federal, e outros deputados oposicionistas, Levy Carneiro e Pedro Calmon, defenderam o restabelecimento da disciplina História do Brasil, todavia o projeto foi arquivado. O debate retornaria por ocasião do Plano Nacional de Educação (RESNIK, 1992; LACOMBE, 1973). De fato, nessa ocasião debateu-se a necessidade de estabelecer o que deveria ser ensinado e quais os programas que melhor atenderiam aos objetivos do ensino secundário. Nessa mesmo momento, evidenciaram-se divergências entre a Associação Brasileira de Educação (ABE), instituição que se posicionava a favor dos estudos modernos e científicos, e o Centro Dom Vital, instituição representativa da ala católica e a favor das humanidades clássicas.

Jonathas Serrano, relator da comissão do ensino secundário do Conselho Nacional de Educação (CNE), pertencia à ala católica e também defendia o retorno da História Pátria. Basílio de Magalhães, relator da resposta do IHGB ao Inquérito de Capanema ${ }^{7}$, posicionava-se a favor do retorno da disciplina História do Brasil e do currículo de orientação científica introduzido por Francisco Campos. O currículo aprovado pelo CNE expressou tendência conservadora, pró-clássica.

A votação do Plano Nacional de Educação (PNE) foi interrompida pelo "golpe de 1937”. O caráter conservador do PNE aprovado pelo CNE ganhou força com o Estado Novo mostrando-se fundamental nas campanhas em prol do ensino de História do Brasil. Os apelos a "Pátria" e ao "patriotismo", centrais no discurso estadonovista, contribuíram para redirecionar o ensino de História.

Várias campanhas foram realizadas pelo IHGB, Colégio Militar do Rio de Janeiro e Correio da Manhã sobre a importância da História do Brasil no ensino secundário ${ }^{8}$. As campanhas encerraram-se com a Portaria n. 49, de 19/03/1940, expedida por Gustavo Capanema: "A partir do ano escolar de 1940, a História do Brasil passará a constituir uma disciplina autônoma da História Universal, no curso fundamental do ensino secundário" (BRASIL, 1940). A partir de então foi ministrada nas $4^{\mathrm{a}}$ e $5^{\mathrm{a}}$ séries paralelamente à História Geral e História da América.

Em 1943 os programas de ensino de História do Brasil para as $3^{\mathrm{a}}$ e $4^{\mathrm{a}}$ séries do curso ginasial vieram à luz. Em 1945 o programa de História do Brasil para o $3^{\circ}$ ano do curso colegial é integrado à matriz comum dos cursos clássico e científico.

\footnotetext{
${ }^{7}$ Em janeiro de 1936, Gustavo Capanema enviou um questionário a diversas instituições, órgãos e personalidades. O questionário objetivava recolher dados de opinião para um inquérito educacional elaborado por educadores com o intuito de confluir a atenção de diversos segmentos da sociedade em torno da elaboração de um plano integral e nacional para a educação.

${ }^{8}$ A esse respeito, cf. Moreira (2011).
} 
As informações a respeito dos programas de ensino para a disciplina História do Brasil permitem concluir que a seriação sofreu alterações significativas. Entre 1931 e 1950, último ano em que vigorou o programa da reforma Capanema, a disciplina foi ministrada em pelo menos duas séries.

Quadro 1: Serração da disciplina História do Brasil entre 1931 e 1945

\begin{tabular}{|l|l|l|}
\hline \multicolumn{1}{|c|}{ Programa } & \multicolumn{1}{c|}{ Disciplina } & \multicolumn{1}{c|}{ Séries } \\
\hline Programa de 1931 & História da América e do Brasil & $3^{\mathrm{a}}, 4^{\mathrm{a}}$ e $5^{\mathrm{a}}$ séries (2 h semanais) \\
\hline Portaria 1940 & História do Brasil & $4^{\mathrm{a}}$ e $5^{\mathrm{a}}$ séries \\
\hline Programa de 1942 & História do Brasil & $3^{\mathrm{a}}$ e $4^{\mathrm{a}}$ séries ginásio \\
\hline Programa de 1945 & História do Brasil & $\begin{array}{l}3^{\mathrm{a}} \text { série do colegial (clássico e } \\
\text { científico) }\end{array}$ \\
\hline
\end{tabular}

Fonte: Programas de Ensino de 1931 a 1945.

A disciplina de História recebeu maior extensão a partir de 1931 quando comparada aos currículos anteriores.

\section{Currículo de História, livros didáticos e autores na Era Vargas}

As mudanças na distribuição dos conteúdos e na seriação da disciplina História do Brasil no curso secundário, a partir do programa de ensino de 1931, ao influenciarem a edição dos livros didáticos, contribuíram para a expansão da indústria livreira. Tal expansão levou ao aperfeiçoamento da indústria gráfica no Brasil e consequente modificação das características materiais das edições escolares no que se refere à aparência, resistência do livro e disposição do conteúdo.

Como parte das mudanças em torno da produção e editoração de livros didáticos no Brasil a partir da década de $1930^{9}$, a Comissão Nacional do Livro Didático, criada em 1938, proibiu a adoção oficial dos livros didáticos. A medida foi justificada com a afirmação de que assim estariam preservando a liberdade de escolha do professor e evitando favorecimentos na opção por determinados títulos.

Com a produção de livros seriados e a criação das Faculdades de Filosofia, cresceu o número de autores didáticos. Professores-autores atraídos pelas compensações financeiras fizeram-se presentes numa conjuntura singularizada pela expansão do ensino secundário.

A esses fatores somaram-se as estratégias editoriais que, tendo em vista a diversidade regional do mercado de didáticos, publicaram vários títulos para uma mesma disciplina e série. O motivo: autor e título com aceitação em São Paulo poderiam não ter a mesma aceitação no Distrito Federal ou em outros estados. Além de concorrer com edições locais,

\footnotetext{
${ }^{9}$ Mais informações em Resnik (1992).
} 
"convinha editar livros da autoria dos professores com maior prestígio local, ou (que) ensinassem em escolas secundárias de crescido número de alunos, ou ainda, (que) não fossem muito recatados na propaganda dos seus livros" (HOLLANDA, 1957, p. 148).

Para Hollanda, analisados em conjunto, os livros didáticos de História de autores brasileiros publicados depois da criação dos cursos universitários demonstravam-se sutilmente melhor no que diz respeito ao quesito informação histórica. Em relação ao conteúdo pedagógico, o autor dizia haver alguma melhoria nos títulos publicados a partir da reforma Francisco Campos. No entanto, "ao se tornar a edição de livros didáticos para o curso secundário, um negócio bem mais lucrativo que em 1930, a multiplicidade crescente de autores não tem contribuído para aprimorá-los pedagogicamente” (Ibid., p. 195).

Entre os autores aqui apresentados, no entanto, nenhum se formou nos cursos universitários de licenciatura recém-abertos no Brasil. Entre os dois autores, Jonathas Serrano era bastante reconhecido na área por tratar das questões em torno do ensino de História, e Joaquim Silva, por sua vez, se tornou famoso pelo grande número de livros didáticos publicados. Ele escreve e publica títulos didáticos entre 1933 a 1971, pelo que temos notícia.

Apresentamos a seguir uma sucinta descrição dos autores e obras selecionadas:

\subsection{Jonathas Serrano e a Epítome de História do Brasil}

Jonathas Arcanjo da Silveira Serrano (1885-1944) formouse em Direito, mas dedicou-se ao ensino de História no Colégio Pedro II e na Escola Normal. Seus livros contribuíram para a constituição de uma pedagogia da História, dado seu interesse pelo método, o "como se ensina".

Atuou em prol da educação juntamente com Afrânio Peixoto, Fernando de Azevedo, Francisco Campos, Lourenço Filho e Gustavo Capanema, dentre outros. Fez parte da comissão de elaboração do anteprojeto da reforma da instrução no Distrito Federal liderada por Fernando de Azevedo. Ocupou a direção da Escola Normal do Distrito Federal e subdiretoria técnica da Diretoria Geral da Instrução Pública e presidiu a ABE.

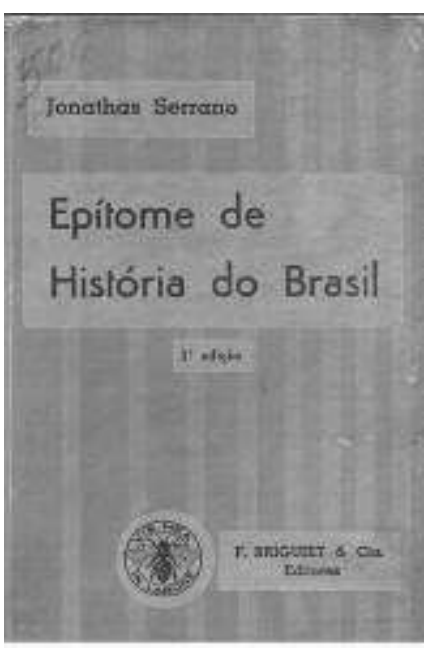

Publicou Epítome de História Universal, 1912, adotado no Colégio Pedro II, Escola Normal do Distrito Federal e em outras instituições de ensino. Em 1917 publicou Metodologia da História na aula primária e em 1935 publicou Como se ensina História, livro de metodologia aplicada ${ }^{10}$. Em 1930, com Venâncio Filho, publicou Cinema $e$ educação e como entusiasta da Escola Nova escreveu Escola Nova, palavras serenas num debate apaixonado, 1932.

Publicou História do Brasil, impresso na França e publicado em 1931, com tiragem reduzida de 200 exemplares, tendo em vista o alto custo devido à quantidade de páginas,

\footnotetext{
${ }^{10}$ Mais informações sobre Como se ensina História, em Moreira (2008).
} 
580, ilustrações e mapas, 121. Revisado por Lucinda Coutinho de Mello Coelho, o livro foi reeditado em 1968.

Epítome de História do Brasil, editado pela Editora F. Briguiet \& Cia, 1933, assemelha-se a História do Brasil do autor, mas não se trata de um mero resumo, pois no dizer de Jonathas Serrano "a diferença é muito mais de plano de exposição, de estrutura interna, de aplicação metodológica do que meramente de volume, calculado em páginas" (SERRANO, 1941, p. 1). O exemplar de Epitome de História do Brasil de Jonathas Serrano aqui analisado pertente a $3^{\mathrm{a}}$ edição, 1941. Contém 251 páginas, 14 capítulos, 47 ilustrações, 43 retratos, quadros cronológicos e sincrônicos, leituras "complementares" e exercícios ao final dos capítulos.

\subsection{Joaquim Silva e História do Brasil}

Joaquim Silva (1880-?) foi professor em diversas instituições de ensino paulista: Liceu Nacional Rio Branco, Colégio Madre Cabrini, Colégio São Luiz e Ginásio das Cônegas de Santo Agostinho. É o autor com maior número de didáticos de História vendidos nas décadas de 1930 e 1940, editados pela Companhia Editora Nacional.

No fichário da Biblioteca Nacional constam os títulos didáticos de Joaquim Silva, (RESNIK, 1992). Entre os 55 títulos do autor constantes no Banco de Dados Livros Escolares (LIVRES) $^{11}$, há títulos relacionados à História Geral, da Civilização, da América e História do Brasil.

Serão dois os exemplares de Joaquim Silva aqui analisados. O primeiro, História do Brasil para o terceiro ano ginasial, $8^{\text {a }}$ edição, 1943, "de acordo com o último programa oficial”. O segundo, História do Brasil para o quarto ano ginasial, $11^{\text {a }}$ edição revista e aumentada, 1944, "de acordo com o último programa oficial", 213 páginas. Ambos, com quadros sincrônicos, ilustrações, "datas notáveis", "sumário" e apontamentos "para exercício escrito". Em síntese, os dois autores foram escolhidos por terem sido os mais difundidos no período de 1930 a 1945 (MOREIRA, 2011). Neste trabalho, utilizamos como critério de seleção a recorrência de títulos entre as fontes disponíveis; a longevidade dos títulos; os autores com maior quantidade de títulos; e os títulos mais investigados em estudos acadêmicos.

\section{Do texto ao contexto: apresentando as obras didáticas}

Neste tópico apresentamos uma análise dos conteúdos históricos e didáticopedagógicos, relacionando o texto dos livros didáticos selecionados ao contexto em que foram elaborados e utilizados. Para tanto, partilhamos do ponto de vista de Lima (1989),

\footnotetext{
${ }^{11}$ Disponível em: http://www2.fe.usp.br:8080/livres/. Acesso em 5 jan 2014.
} 
para quem a narrativa é organização temporal, colocando o diverso, o irregular e o acidental em ordem.

\subsection{Epítome de História do Brasil, de Jonathas Serrano}

Em Epitome de História do Brasil, Jonathas Serrano não segue rigorosamente o programa de ensino. Na primeira edição (1933), vigorava o programa de ensino de 1931; na terceira (1941), vigorava o programa de 1940.

Como vimos, o programa de 1931 não apresentava História do Brasil como disciplina autônoma, mas integrada à História Geral da Civilização. Portanto, para atender o estipulado, o autor fez constar no livro as definições de História e Pré-História, História Antiga, Média e Moderna. Com esse recurso metodológico situou a História do Brasil em âmbito maior. O que nos permite evidenciar que não houve mudanças na estrutura proposta pelo autor, entre a primeira edição de 1933 e a terceira de 1941. Inclusive porque, como escreveu, optou por não seguir "cegamente a programas".

Já na página inicial de Epitome, Jonathas Serrano valoriza o professor ao referir-se ao programa curricular: "Um programa nada vale sem um espírito que o anime, o fecunde e o faça frutificar" e "Este programa vivo é, deverá ser, dentro da própria capacidade, cada professor". (SERRANO, 1941, p. 1).

O autor não se prendeu a programas de ensino com a justificativa de que eles variavam conforme as circunstâncias; a mudança, dizia Serrano, nem sempre "é sinônimo exato de aperfeiçoamento". Mais ainda, fundamentado em Edouard Claparède, também afirmava: "nada vale um programa por si só".

Jonathas Serrano organizou o livro em capítulos contendo narrativas até então desdobradas em mais de um capítulo: "Ver-se-á também que usamos aqui de outros processos na seleção cronológica", ou seja, a prioridade do ensino estava no método e não apenas no conteúdo histórico. Questionador da "enfadonha exposição de datas e fatos e da memorização", o autor propunha, em conformidade com as novas correntes pedagógicas, uma pedagogia capaz de valorizar a análise crítica em conformidade com a idade do aluno e seu grau de adiantamento.

As "noções preliminares" em Epitome são destinadas aos alunos mais adiantados e aos professores: "Nada aqui se há de exigir de cor, como assunto obrigatório. São apenas para leitura, consulta propositada e como advertência de que nunca se há de isolar a História Pátria da História da Civilização Humana". (SERRANO, 1941, p. 7).

Com o intuito de conciliar História do Brasil e da Civilização o autor organizou cinco "quadros sincrônicos", do século XVI ao XX, com acontecimentos da história geral e do Brasil. Sobre os quadros, sejam sincrônico, sinótico ou cronológico, Jonathas Serrano afirma: "os quadros, só por si, são insuficientes e até prejudiciais", pois mostravam apenas o "esqueleto" [...] "é indispensável cobrir de músculos e nervos, isto é, dar vida a esse esqueleto. Só a explicação oral, animada, viva, com minúcias, com episódios narrados, pode obter esse resultado final" (SERRANO, 1935, p. 41). 
As "leituras" somadas às "anedotas" e "gravuras e mapas" iria "interessar os leitores, que nem sempre são porventura somente estudantes em vésperas de provas" (SERRANO, 1941, p. 2). O autor distingue o conteúdo "destinado" e o "não destinado" a ficar na memória dos leitores. Os não destinados a ficar na memória dos leitores seriam os que constam nas "biografias" e "quadros cronológicos", enquanto que o texto de cada capítulo seria o conteúdo que deveria ser memorizado. Os esboços biográficos são tidos como "novidade" e "destinam-se a familiarizar desde logo o aluno com a minúcia biográfica, em caso de consulta necessária a fontes de informação mais desenvolvidas. Nunca, em hipótese alguma, serão exercícios de memorização", assim como os "quadros cronológicos". Esses recursos didáticos contribuem para "habilitar o aluno a informar-se por si, consultando ao menos o próprio manual" (Ibid., p. 2).

Sobre as biografias Jonathas Serrano situava-as como recurso de compreensão do papel dos grandes personagens no passado, recurso aconselhável para as classes mais atrasadas. Alertava: adoção exclusiva desse recurso implicaria na exageração da pessoa biografada.

O autor propõe nos capítulos dois tipos de exercícios: completar frases e identificar frases certas e erradas. $\mathrm{Na}$ maioria dos capítulos propõe também exercícios "para alunos mais adiantados", do tipo: "a importância histórica", "o porquê", "as causas" dos fatos. Havia ainda "exercícios elementares de crítica" e "exercício para aplicação do desenho".

Jonathas Serrano, em Como se ensina História (1935, p. 13), posicionava-se contrariamente "ao emprego de questionários rígidos, pré-estabelecidos para todas as turmas da mesma série, em qualquer ano letivo". Propunha exercícios elementares e complexos.

No mais, alertava: perguntas claras, concatenadas, graduadas ao nível mental dos discípulos não provocariam enfado e temor. Em conjunto, os exercícios não estariam “apenas destinados à memória, mas igualmente ao raciocínio". Portanto, o que se nota é a estimulação de respostas ativas. Ao variar os tipos de exercícios procurava evitar a memorização e a padronização.

Passando para o conteúdo histórico, ao narrar o "Descobrimento do Brasil", Jonathas Serrano aborda a tese do "acaso do descobrimento", anteriormente exposta no seu História do Brasil (1931). Referenciando-se em $O$ descobrimento do Brasil pelos portugueses (1929), de Capistrano de Abreu, Jonathas Serrano dizia tratar-se de "um ponto muito debatido da história do Brasil, e que talvez nunca terá solução decisiva" [...], pois "se existem razões fortes para o acaso do descobrimento, também existem outras, não menos valiosas, que nos levam a crer na intencionalidade da derrota da armada lusitana" (SERRANO, 1941, p. 40).

A questão consta originariamente no programa de 1940, no ponto: "O descobrimento. Pontos controvertidos: crítica". Jonathas Serrano trata da polêmica "acaso ou intencionalidade do descobrimento" do Brasil, antes mesmo de o tema constar nos programas de ensino. Essa observação contribui para pensar a influência dos livros didáticos e seus autores na elaboração dos programas de ensino nesse contexto.

Quanto à contribuição das etnias para a formação do Brasil, Jonathas Serrano expõe o tema nos capítulos "O elemento indígena" e "O elemento negro".

O autor explica didaticamente as "tribos selvagens", o "estado de civilização do indígena brasileiro", a "catequese" e a "importância do elemento indígena". O programa de 1940 
estipula que o índio deveria ser tratado no que dizia respeito à "etnografia e etnologia do selvagem", como constava no tópico II. A importância do elemento indígena é sugerida nos programas de 1942 e 1951. O livro didático de Jonathas Serrano apresenta abordagem inovadora posteriormente incorporada ao programa.

A influência exercida pelos indígenas, segundo esse autor, está "na própria língua portuguesa falada no Brasil" e "também no domínio do folclore”. A contribuição do "elemento negro", por sua vez, é explicada no contexto do Segundo Reinado, ao tratar da Abolição. É quando dedica um capítulo sucinto ao quilombo dos Palmares sem, no entanto, introduzir explicações inovadoras, quando comparado a outros autores didáticos (MOREIRA, 2001). Nesse capítulo, Serrano reforça uma tendência na literatura didática, preocupada em assinalar as mazelas da escravidão e os sofrimentos do negro. Ao contrário dos indígenas, considerados "rebeldes e avessos ao trabalho pesado" e tendo a proteção dos jesuítas, "os negros sem proteção legal, eram tratados como animais pelo feitor, sempre disposto a punir de chicote, ou mais cruelmente ainda, qualquer falta cometida. Viviam nas senzalas, amontoados sem higiene nem conforto algum". (SERRANO, 1941, p. 159).

$\mathrm{Na}$ escrita do autor, era como se a sociedade da época reconhecesse os erros do passado e idealizasse o presente e o futuro como tempos melhores. Todavia, amenizou a narrativa ao escrever que no Brasil os negros eram "mais feliz ou menos desgraçados que noutros países, inclusive as colônias norte-americanas. Muitas vezes o escravo ou escrava se tornava querido dos senhores e sobretudo das crianças" (Ibid., p. 159-161). Para Resnik (1992), essa "positivação" traduz um movimento de valorização do trabalho, difundido nos livros didáticos no período estadonovista.

Quanto à contribuição do negro, Serrano assinala uma grande e natural influência: "A afetividade da Mãe Preta é um fato comovedor de nossa história doméstica e social" (Ibid., p. 163). Como que ilustrando tal assertiva, o livro reproduz um quadro de Jean Baptiste Debret - D. Pedro II, ainda na infância, repousa no colo de uma mucama, destacando as "qualidades boas ou menos felizes que herdamos dos negros".

$\mathrm{O}$ ato de relevar as influências de negros e indígenas na formação do povo brasileiro é uma constante na produção didática. No entanto, Jonathas Serrano imprime maior fôlego a esse tipo de análise. De fato o tema da influência das "três raças" fortaleceu na Era Vargas quando o discurso da construção da nação pela "união das raças" é contraposto ao "regionalismo desagregador". Sobre os temas "invasões" estrangeiras, movimentos nativistas, guerra do Paraguai, o autor assim se posicionava:

Notará o leitor atento que reduzimos ao mínimo indispensável tudo quanto se relaciona com a guerra. [...] O ideal seria nem falar nas guerras. Infelizmente é preciso dizer alguma coisa das mais importantes, sob pena de mutilar, falseando-o, o nosso conhecimento do passado nacional. [...].

Há mais de um decênio já observávamos a este respeito: “O patriotismo moderno, que não tem o horizonte acanhado como o dos Gregos ou Romanos, é um sentimento elevado, que o Cristianismo depurou do que tinha de bárbaro, egoísta e injusto. 


\begin{abstract}
Além das fronteiras da pátria há outros povos; e, se os não podemos amar como o nosso, não os odiamos como inimigos, nem desconhecemos os seus direitos naturais e inalienáveis. $\mathrm{O}$ verdadeiro nacionalismo [...] é o culto da língua, das tradições, dos traços característicos da pátria; é o combate à imitação servil dos costumes de outras gentes; é o esforço inteligente e bem orientado para que se mantenha a coesão nacional"*. Rio, 1933. (SERRANO, 1941, p. 3-4).
\end{abstract}

Fosse por sua formação católica, fosse pelo contexto de entreguerras mundiais, o autor amenizava a narrativa da guerra ao adotar um espírito pacifista.

Quanto às "invasões" estrangeiras, escrevia: "a luta continuou no Brasil entre os filhos da colônia, que desejavam expulsar os "invasores", e estes últimos (os holandeses), decididos a não perder as conquistas efetuadas" [...], "combatendo o inimigo comum, brancos, negros e índios uniram-se melhor. Aponta na resistência heroica ao invasor, certo sentimento de autonomia" (Ibid., p. 64-67).

Quanto à "Inconfidência Mineira", para o autor os "inconfidentes" desejavam "proclamar a República, fundar uma Universidade em Vila Rica e várias fábricas em diversas localidades, abolir a escravidão e fixar a capital da república em S. João d'El-Rei" (Ibid., p. 110). Os inconfidentes teriam sido influenciados pelo Contrato Social de Rousseau.

A Revolução Pernambucana de 1817 é descrita como movimento republicano. Sobre a guerra contra o Paraguai, Jonathas Serrano é sucinto ao concluir que se tratou de uma "guerra mortífera", cinquenta mil mortes causadas pelos combates e o cólera, deixando o Brasil endividado, e o Paraguai arruinado.

No capítulo "O clero na formação nacional", Jonathas Serrano expõe o trabalho "admirável" dos jesuítas, responsáveis pela "força moral", essencial à formação da nacionalidade. O autor critica a expulsão dos jesuítas em 1759, tendo sido "acusados injustamente de serem responsáveis pelo mau êxito das demarcações consequentes ao Tratado de Madri e pela sublevação dos índios" (SERRANO, 1941, p. 184), e a condenação dos bispos quando do conflito entre católicos e maçons, a chamada "questão religiosa", 1872-1875. Ao sintetizar os quatro séculos da história do Brasil, o autor constatou a desunião das três raças e que "a corrupção teria sido medonha, se não fosse a ação moral dos Jesuítas" (Ibid., p. 212). Relevou as ações do clero católico nos movimentos revolucionários de caráter republicano. Ao explicar a separação entre Igreja e República, concluía as "vantagens- evidentes" — livre da autoridade civil, a "Igreja tomou novo desenvolvimento" (Ibid., p. 188).

Os bandeirantes foram abordados no capítulo "Geografia e delimitação definitiva" do território. Sem dúvida, o primeiro autor a dedicar-se à questão da demarcação das fronteiras fora João Ribeiro; Jonathas Serrano inovou, por sua vez, ao abordar o tema

\footnotetext{
* Nota do autor: "Em nossa "Filosofia do Direito", pags. 217-218 (Livraria Drummond, ed - Rio de Janeiro, 1920)".
} 
“entradas e bandeiras" quando tratou da expansão e delimitação geográfica do Brasil. Inicialmente o tema expansão e delimitação do território constou em Epitome de História do Brasil, e depois no programa de ensino de 1942, na unidade "Expansão Geográfica", incluindo "os centros iniciais da vida colonial", a conquista das regiões setentrionais, as "entradas" e as "bandeiras" e os tratados de limites.

No capítulo, o autor engloba a discussão sobre a "conquista e colonização do norte", e, ao analisar as "entradas e bandeiras", cita Capistrano de Abreu, menciona os bandeirantes mais conhecidos, exemplifica as relações conflituosas entre "as reduções, os índios e os bandeirantes", explica os "tratados de Madri e de Santo Ildefonso" e, por fim, apresenta a "delimitação definitiva" do território. Para ele as ações do Barão do Rio Branco foram decisivas na solução das questões de fronteiras.

Quanto ao Império, Jonathas Serrano menciona as lutas civis travadas nas regências destacando a "chamada Guerra dos Farrapos" no Rio Grande do Sul que "só terminou graças à energia e habilidade de Caxias" (Ibid., p. 144). Assim, o autor atendia o programa oficial de 1940, que acrescentou ao Segundo Reinado, o tópico "Caxias e a unidade nacional". No entanto, essa inovação já constava em História do Brasil (SERRANO, 1931), no capítulo "Caxias e a unidade do Império".

Para tratar da República, Serrano escreve os capítulos "O período republicano" e "A revolução de Outubro e o Estado Novo", delimitando assim o período: "Proclamação da República até Outubro de 1930, quando Washington Luís é deposto pela "Revolução". O autor narra sucinta e ponderadamente os governos presidenciais. No tópico "Deodoro e Floriano", o segundo é mais reconhecido: "é justo dizer que a sua firmeza, por vezes implacável, salvou o prestígio da autoridade e consolidou a república" (Ibid., p. 198).

No último capítulo o autor interpreta a Revolução de Outubro de 1930 como consequência de "erros graves": a "escolha do sucessor imediato do então chefe do governo" e a "ideia da imposição de uma candidatura impopular" levaram a "inevitável reação nacional" (Ibid., p. 233). Na sequência, a "revolução" atingiu o "sul, centro e norte do país", configurando-se como o "maior e o mais importante acontecimento da nossa história política".

A década de 1930 foi assim periodizada: de 1930 a Constituição de 1934, de 1934 à implantação do "Estado Novo" em 1937, “de 1937 até nossos dias”. Nessas etapas e

de modo crescente, se viu acentuando o desenvolvimento do programa ideado pelos chefes da Revolução de Outubro. [...] o Presidente Getúlio Vargas soube, nas três fases deste decênio, manter a coesão nacional, sufocar tentativas de sublevação ou até revoltas de caráter grave, e - o que merece especial relevo aumentar cada vez mais o seu prestígio pessoal. (Ibid., p. 234).

Ao final, ilustra o decênio com dados estatísticos demonstrativos do crescimento econômico-social. Certamente o capítulo anterior - "A obra de quatro séculos" - visava permitir aos alunos-leitores comparar os progressos de quatrocentos anos com o decênio capitaneado por Getúlio Vargas, e levá-los a concluir pela superioridade dos tempos atuais. 
Para Jonathas Serrano o "Estado Novo" foi uma tomada de poder a fim de restabelecer a paz, a harmonia e a tranquilidade social.

Como leitura complementar, o autor propôs "A riqueza do Brasil”, extraído de Brasil 1939-1940 (publicação do Ministério das Relações Exteriores), "O movimento de 1930" de Getúlio Vargas (Discurso de 4 de outubro de 1930, em Porto Alegre) e "O Brasil e a América” também de Getúlio Vargas (A Nova Política do Brasil, III vol. p. 66).

\subsection{História do Brasil, de Joaquim Silva}

Em História do Brasil para o $3^{\circ}$ ano ginasial e História do Brasil para o $4^{\circ}$ ano ginasial, Joaquim Silva segue rigorosamente o programa de 1942, anunciando na capa dos livros: "De acordo com o último programa oficial". Para cumprir com o programa vigente e didatizar a exposição das 14 "unidades temáticas" exigidas, o autor destina mais de um capítulo para cada unidade. Na maioria dos capítulos constam, ao final do texto principal, "datas notáveis", "sumário" "exercícios" e "leituras".

Em "Exercícios", constam pontos principais do conteúdo, que deveriam se transformar em questionários, provavelmente, pelo professor. Em "Leituras", constam textos escritos pelo próprio autor para aprofundar a compreensão de temas ou personagens. Joaquim Silva utiliza-se como recurso didático de notas explicativas e bibliográficas, como fez Serrano.

No fecho de cada livro consta um "quadro sincrônico": no livro do $3^{\circ}$ ano, o quadro refere-se ao período de 1500 a 1822 ; no do $4^{\circ}$ ano, há uma cronologia simultânea dos acontecimentos.

Passando para os conteúdos históricos, ao explicar o "Descobrimento", Joaquim Silva remonta à Carta de Pero Vaz de Caminha e aos interesses comerciais como causa das grandes navegações. Como "leitura complementar", propõe a leitura de "As especiarias [Segundo F. A. Kirkpatrick, Los Conquistadores Españoles, 278 e segs.]”.

Sobre "a formação étnica", escrevia que nem todos os degredados enviados de Portugal para a colônia eram criminosos, ladrões ou assassinos: "Naquele tempo condenava-se ao degredo e a outras penas maiores por motivos que hoje nem constituem delitos puníveis, havendo assim, entre os degredados, gente realmente honesta e trabalhadora". Essa ressalva se justifica pela valorização da raça branca como elemento formador da nacionalidade: "segundo escreve Martius, o grande rio cujos afluentes foram o índio e o africano" (SILVA, 1943, p. 86).

Os indígenas são descritos conforme as origens e classificados em grupos principais e menores. Joaquim Silva reconhecia haver "diferenças de certos costumes entre os diversos grupos ou mesmo entre tribos do mesmo grupo", mas diz que muitos desses hábitos "eram comuns a todas elas". Quanto às influências indígenas, dizia "serem notáveis nos costumes e na língua dos brancos", poucos e esparsos, os portugueses "se deixaram dominar pelos hábitos da terra", passaram "a imitar os selvagens na rude e livre vida". (Ibid., p. 98-99). 
Sobre "o negro", o tratamento é igualmente colonialista: "da África, terra de escravidão, era possível trazer, aos milhares, pretos que já eram escravizados por seus régulos e que, vindo para o Brasil, trocavam um cativeiro por outro, aliás, menos desumano que o sofrido na terra natal". (Ibid., p. 101). Sobre a influência do negro, assim como Jonathas Serrano em Epitome de História do Brasil, Joaquim Silva deduzia, baseado em "antiga crônica" de Antonil ${ }^{12}$, que "os escravos são as mãos e os pés do senhor de engenho, porque sem eles, no Brasil, não é possível fazer, conservar ou aumentar a fazenda, nem ter engenho corrente" (Id.). Além do aporte econômico, a influência do negro poderia ser vista "na constituição do tipo brasileiro, na formação moral, nos usos e costumes, e até na linguagem".

A conjunção adversativa "mas" serve para reforçar a tese de que, apesar das más heranças herdadas dos negros, a passividade é o elemento qualificativo. Ou seja, se não há resistência, não há lugar para narrar os quilombos e as revoltas.

No programa de ensino de 1942 para a $4^{\text {a }}$ série do ginasial, o tema da escravidão negra comparece na unidade "A abolição". Ao explicar o tema, o autor cita Gândavo: a vantagem em escravizar "africanos" e não os "selvagens" estaria no fato de que os negros "nunca fogem".

Para o autor os castigos infligidos aos escravos referiam-se aos "casos de delitos de assassínio ou outros de notável gravidade". Em geral "as leis vigentes" e a "índole benévola da maioria dos senhores, inspirados pela religião", suavizavam o cativeiro.

O autor previa o embranquecimento da população como consequência da "situação estacionária da raça negra e redução do fator indígena".

Quanto à narrativa sobre a "expansão geográfica" também distingue entradas e bandeiras. A observação que fazemos diz respeito à influência de João Ribeiro com História do Brasil curso superior, nos argumentos de Joaquim Silva, isto é, a valorização das entradas e bandeiras na expansão do território, e na formulação da unidade, conforme estipulada pelo programa de 1942, ou seja, "a delimitação das fronteiras do país: os bandeirantes, os criadores de gado e os jesuítas, o reconhecimento internacional dos tratados de limites" (p. 120).

Ao narrar a "defesa do território" e as "invasões" estrangeiras, Joaquim Silva expõe a deserção de Calabar, releva a administração do "Conde de Nassau, governador do Brasil holandês de 1636 a 1644", cujo retrato feito por Van Dallen ilustra o capítulo, elucida as vantagens do domínio holandês e aponta a expulsão como uma "heroica reação dos brasileiros". Joaquim Silva cita Capistrano de Abreu: "sob a pressão externa operou-se uma solda, superficial, imperfeita, mas um princípio de solda, entre os diversos elementos étnicos" (p. 139).

A narrativa sobre o "progresso nacional no Império" constante no $4^{\circ}$ ano ginasial é otimista: destaca o café como elemento de riqueza, a borracha e o crescimento do

\footnotetext{
${ }^{12}$ Crônica do jesuíta André João Antonil, em Cultura e opulência do Brasil por suas drogas e minas, Lisboa, 1711, capítulo IX: "Como se há de haver o senhor do engenho com seus escravos".
} 
comércio, alude à política protecionista e o "espírito empreendedor" de Irineu Evangelista de Souza, "o grande Mauá".

As observações sobre o "desenvolvimento espiritual" certamente traduzem sua posição católica, com efeito, demonstra-se partidário da Companhia de Jesus e contrário à expulsão dos jesuítas: "Pombal iniciou tremenda campanha contra os inacianos que, por fim foram expulsos, de modo brutal, das terras a que, por duzentos anos, vinham proficuamente consagrando o melhor de suas energias e perseverante devotamento (1759)" (p. 176). No tópico "Desenvolvimento cultural da colônia", Joaquim Silva enumera os aspectos negativos da expulsão dos jesuítas no tocante à educação.

A narrativa em torno do "sentimento nacional" ressalta a religiosidade do inconfidente Tiradentes: "homem de caráter nobre, sinceramente religioso e exaltado amigo da liberdade" e ao afirmar que o triângulo que compunha a bandeira dos inconfidentes fora desejado por Tiradentes "em honra da SSma. Trindade" (p. 211).

No segundo livro para o $4^{\circ}$ ano ginasial, o Período Regencial mereceu pouca atenção por parte do autor, no tópico "A política interna do Segundo Reinado", destaca a "Guerra dos Farrapos", mas no conjunto dedicou pouca atenção aos movimentos revoltosos, e quando o fez enalteceu o Duque de Caxias.

$\mathrm{O}$ período republicano corresponde à metade do livro para o $4^{\circ}$ ano ginasial. Seguindo as orientações do programa oficial, a primeira e a segunda repúblicas são analisadas quanto à política interna e a política externa. Quanto ao "advento da República", o autor destaca o desgosto dos senhores de escravos com a abolição, a "questão militar" e a "questão religiosa". Na política externa, releva as ações diplomáticas do Barão de Rio Branco, como requeria o programa vigente. Narra a disputa dos territórios das Missões, Amapá e Acre e esboça a biografia do diplomata.

Quanto às realizações administrativas, destaca a restauração financeira, a transformação do Rio de Janeiro em "capital moderna", a construção de estradas e portos e o melhoramento das condições das Forças Armadas.

Em narrativa pormenorizada, como requeria o programa, explica a Segunda República pelos "antecedentes" da "Revolução de Outubro". Quanto ao golpe de Estado de 1937, é detalhista. Define o Estado Novo como "um estado nacional e popular, criado pela Nação e para a Nação, pelo povo e para o povo" (Ibid., p. 190). O pensamento dominante do governo, em sua política interna, foi, segundo o autor, a "unidade do Brasil".

Quanto à política externa adotada pela Segunda República, ressalta a "política de paz", no mesmo capítulo explica a posição do governo contra os "países do Eixo". Conforme exigência do programa de ensino, o autor enaltece Getúlio Vargas: como governante do país, foi "calmo, mas enérgico, longânime, mas severo, tolerante, mas inflexível” (SILVA, 1944, p. 189).

Outro capítulo é dedicado às realizações do "Estado Novo" para a solução dos problemas nacionais. E para a "mais perfeita ideia dos últimos progressos alcançados por nossa pátria, é útil fazer-se uma síntese das jornadas vencidas durante os quatro séculos de história" (Id.).

No fecho do segundo livro, também apresenta uma síntese da História do Brasil na qual se evidencia o "progresso geral” advindo com a Revolução de 1930 e o Estado Novo. 


\section{Considerações finais}

Apesar de o tema do universalismo ter sido um dos destaques nos meios educacionais brasileiros e internacionais na Era Vargas, atribuindo à educação escolar papel decisivo na formação de mentalidades pacifistas e universalistas, o ensino da história nacional prevaleceu, com o argumento comum de que a exclusão da História do Brasil no contexto escolar poderia gerar um povo sem caráter (RESNIK, 1992). Tal discurso foi predominante porque correspondia às necessidades do governo Vargas. Desse modo, os autores didáticos exaltam primordialmente o momento atual, a Era Vargas, em que a Revolução de Outubro de 1930 aparece como "inevitável reação nacional" configurandose como o "maior e o mais importante acontecimento da nossa história política". E o "Estado Novo" como uma tomada de poder a fim de restabelecer a paz, a harmonia e a tranquilidade social.

A relação entre a passividade e o catolicismo é percebida em ambos os livros. Tanto Serrano quanto Silva são assumidamente católicos. O tema da escravidão aparece sob o título "Abolição" e a narrativa predominante é a da cordialidade entre negros escravos e senhores brancos e a sujeição dos negros à escravidão que, ao contrário dos índios, não fugia. A questão dos Quilombos é amenizada, pois não há espaço para narrativas que destaquem revoltas e guerras. Ao contrário de livros didáticos elaborados em períodos anteriores (Cf. Moreira, 2011), que carregaram nos temas sobre guerras, os autores aqui analisados dedicaram pouco espaço aos movimentos revoltosos em suas narrativas e valorizaram os atos católicos, como a importância dos jesuítas para a formação da educação no Brasil. Fosse pela formação católica, fosse pelo contexto entreguerras mundiais, fosse por outro motivo que escapa ao escopo deste trabalho, os autores amenizaram a narrativa a respeito de guerras, adotando um espírito pacifista.

Jonathas Serrano antecipa-se ao conteúdo proposto pelos programas curriculares em muitos temas, dentre eles, a questão dos pontos controvertidos e a crítica em torno do "acaso ou intencionalidade do descobrimento" do Brasil"; a importância dos elementos negro e indígena na formação do povo brasileiro; a relação entre a extensão geográfica e as entradas e bandeiras; e a valorização da figura de Duque de Caxias como herói republicano. A questão aqui não é sobre o pioneirismo de Serrano na abordagem dos temas - muitos deles foram apresentados antes, por João Ribeiro, em História do Brasil: curso superior, publicado em 1900 -, mas sobre sua antecipação à prescrição desses conteúdos e abordagens nos programas curriculares.

A Era Vargas foi marcada pelas reformas do ensino secundário e pela elaboração de programas. Notamos que alguns conteúdos apareceram primeiro em livros didáticos e depois na forma de programas. Isso aconteceu com as obras de Serrano que, como apresentamos, teve influência na elaboração dos programas curriculares, incorporando tanto conteúdos didáticos do método renovador - característico da Escola Nova, e a apologia católica - típica do seu discurso conciliador, como a inauguração de abordagem de alguns conteúdos históricos, nos seus didáticos e nos programas. Joaquim Silva, por sua vez, segue rigorosamente os programas, como ele mesmo afirma, com o intuito de corresponder ao mercado de didáticos, em franca expansão no período em questão. 
Oriundo de Casa Grande e Senzala (Gilberto Freyre) e Raízes do Brasil (Sérgio Buarque de Holanda), o tema da influência das "três raças" se fortalece na Era Vargas, nos livros didáticos e programas curriculares, como discurso nacionalista em oposição ao regionalismo que desagrega. Nos títulos analisados, o conceito de "povo-nação" vincula-se à figura do Estado tido como elemento crucial da unidade nacional. No campo político, na chamada Era Vargas e mais explicitamente no Estado Novo, a teoria da miscigenação tornou-se estratégica na empresa de divulgação da ideologia da união das raças em torno da nação. A "teoria da miscigenação" torna-se integrante da ideologia estadonovista.

As relações em torno do trabalho constam nas narrativas de Jonathas Serrano e Joaquim Silva ao se referirem ao povo. Ao explicar os índios como avessos e os negros como aptos ao trabalho, Jonathas Serrano ressaltava o trabalho produtivo como fator essencial nas relações sociais, desde os primórdios da colônia. Joaquim Silva, por sua vez, ao postular que entre os portugueses degredados haveria gente honesta e trabalhadora, e, ao mesmo tempo, postular a falta de amor ao trabalho por parte dos negros, igualmente reforçava a importância do trabalho para a sociedade em formação. A narrativa predominante nos livros didáticos dos anos 19301940 contribuía para a formação de trabalhadores disciplinados, agentes da modernidade desejada desde os tempos de outrora. As relações amenas e harmônicas entre as raças eram exemplificadas com frequência pela história do Brasil.

Alia-se, aos fatores historiográficos e políticos, o movimento educacional da Escola Nova, que buscava, segundo Monarcha (1989), mobilizar ideológica e politicamente as classes sociais, para superar o atraso nacional e ingressar na modernidade. Os escolanovistas produziram um imaginário centrado no embate entre velho e novo, racional e irracional, antigo e moderno (MONARCHA, 1989), e, nesse sentido, o "ensino renovado", em contraposição ao antigo "ensino tradicional", pretendeu garantir espaço nos livros didáticos, apresentando uma metodologia que não valorizasse a passividade e a memorização, mas a atividade e o comportamento inteligente, por meio de biografias, leituras subsidiárias, questionários graduados e trabalho em equipe, sempre orientado pelo professor.

Por fim, vale destacar que nesse contexto de "ensino renovado" proposto pela Escola Nova, não se questionava a importância do livro didático no processo de ensino aprendizagem. Para Jonathas Serrano, só duvidaria da necessidade de um "bom livro didático" quem não tivesse prática de ensino. No entanto, os livros didáticos tradicionais exigiam leitura árida e exaustiva, enquanto que os livros modernos seriam impressos com recursos variados: redação graduada, rico em estampas e mapas, leituras complementares e esquemas de recapitulação. Sobretudo, o "bom livro didático" estaria atualizado com a crítica historiográfica e as pesquisas arqueológicas e etnológicas. Ao professor caberia reavivar as "páginas da História".

\section{Fontes}

SERRANO, J. Epitome de História do Brasil. 3. ed. Rio de Janeiro: F. Briguiet \& Cia editores, 1941.

SILVA, J. História do Brasil para o terceiro ano ginasial. 8. ed. São Paulo: Nacional, 1943.

História do Brasil para o quarto ano ginasial. 11. ed. São Paulo: Nacional, 1944. 


\section{Referências}

BRASIL. Departamento de Educação Técnico-Profissional, 19 de abril de 1940. Diário Oficial da União, Edital n. 5, 19 abr 1940. Rio de Janeiro, RJ, Seçao II, p. 25. Disponível em: http://www.jusbrasil.com.br/diarios/2225705/pg-25-secao-2-diario-oficial-da-uniaodou-de-19-04-1940/pdfView. Acesso em: 10 maio 2014.

CAPISTRANO DE ABREU, João. O descobrimento do Brasil pelos portugueses. In $O$ descobrimento do Brasil, Rio de Janeiro, Livraria Briguiet, 1929, pp. 93- 117. [Primeira edição de 1883].

CHERVEL, A. História das Disciplinas Escolares: reflexões sobre um campo de pesquisa. Teoria \& Educação, Porto Alegre, n. 2, p. 177-229, 1990.

CHOPPIN, A. Les manuels scolaires: histoire et actualité. Paris: Hachette Éducation. 1992. CUNHA, L. A. Educação e desenvolvimento social no Brasil. Rio de Janeiro: Francisco Alves, 1980.

GUEDES, J. A. L. Curso de didática de História. Rio de Janeiro: J. Ozon Editor, 1963.

HOLLANDA, G. de. Um quarto de século de programas e compêndios de História para o ensino secundário brasileiro (1931-1956). Rio de Janeiro: INEP/CBPE, 1957.

JULIA, D. A cultura escolar como objeto histórico. Revista Brasileira de História da Educação. Campinas, SP:SBHE/Ed. Autores Associados, $1^{\circ}$ número, 2001.

LACOMBE, A. J. Introdução ao estudo da História do Brasil. São Paulo: NacionalEDUSP, 1973.

LIMA, L. C. A aguarrás do tempo. Estudos sobre narrativa. Rio de Janeiro: Rocco, 1989.

MAGALHÃES, J. O manual escolar no quadro da História Cultural. Para uma historiografia do manual escolar em Portugal. Sísifo. Revista de Ciências da Educação, 1, p. 5-14, 2006.

MONARCHA, C. A reinvenção da cidade e da multidão. Dimensões da modernidade brasileira: a Escola Nova. São Paulo: Cortez, 1989.

História da educação brasileira (esboço da formação do campo). In: NASCIMENTO, M. I. M.; SANDANO, W.; LOMBARDI, J. C.; SAVIANI, D. (Orgs.). Instituições escolares no Brasil: conceito e reconstrução histórica. Campinas, SP: Autores Associados, 2007, p. 120-145.

MOREIRA, K. H. O ensino de história do Brasil no contexto republicano de 1889 a 1950 pelos livros didáticos: análise historiográfica e didático-pedagógica. 2011. 236 f. Tese (Doutorado em Educação). Universidade Estadual Paulista, Araraquara, 2011.

. Sensibilidades e sociabilidades em "Como se ensina História" (1935) de Jonathas Serrano. In: IV SIMPÓSIO NACIONAL DE HISTÓRIA CULTURAL. 2008, Goiânia. Anais... Goiânia: Ed. da UCG, 2008. v. 1. p. 382-383.

RESNIK, L. Tecendo o amanhã (a história do Brasil no ensino secundário: programas e livros didáticos. 1931-1945). Rio de Janeiro, 1992. Dissertação (Mestrado em História) Universidade Federal Fluminense.

ROMANELLI, O. História da educação do Brasil. 5. ed. Petrópolis: Vozes, 1978. 